\title{
La tiroides y su influencia sobre la función gonadal.
}

\section{Dr. FABIO SANCHEZ ESCOBAR}

\section{A. EMBRIOLOGIA}

La glándula tiroides inicia su diferenciación a partir del día 17 de vida embrionaria, cuando a nivel de la línea media del piso de la boca aparece una proliferación endodérmica, a nivel de la faringe primitiva, que se invagina a manera de divertículo y se proyecta caudalmente hasta localizarse definitivamente delante de la tráquea, alrededor de la séptima semana, quedando unida al piso de la boca por un pequeño conducto denominado conducto tirogloso, el cual se atrofia. En ocasiones dicho conducto persiste, dando lugar a una dilatación sacular denominado quiste tiroglaso, que puede ser reservario de tejido tiroideo ectópico.

Durante la octava semana de vida em brionaria, el divertículo se subdivide originando dos lóbulos laterales los cuales se unen entre sí en la línea media y originan la glándula definitiva.

\section{B. HISTOLOGIA}

La glándula está constituída por múl tiples acinos o folículos que asientan sobre una membrana basal que los separa del estroma.

Los folículos son la unidad funcional y están constituídos por una línea de células epiteliales, las cuales son cúbicas cuando están en reposo y columnares cuando están en actividad, tienen la capacidad de sintetizar coloide, a partir de la 13a. semana y de almacenarlo en el interior del folículo. Se calcula que el coloide constituye el $76 \%$ del total del peso de la glándula.

Los folículos tienen cerca de $200 \mathrm{mi}$ cras de diámetro, que unidos en grupos de 20 a 40 constituyen lóbulos ti-

* Hospital Universitario San Vicente de Paul Medellín Colombia. Profesor Facultad de Medicina Universidad de Antioquia. roideos y que en conjunto conforman la glándula.

En el estroma del tiroides se encuentran unas células parafoliculares o células $C$, que tienen la capacidad de secretar Calcitonina, hormona que interviene, con la hormona paratiroidea en la regulación del calcio serico.

\section{ANATOMIA}

La glándula tiroides consta de dos lóbulos laterales unidos entre sí, en la lí. nea media, por el istmo, de donde se desprende una prominencia superior denominada pirámide de Lalouette, vestigio del conducto tirogloso. Está situado en el cuello, delante de la traquea y debajo del cartílago cricoides, rodeada por una cápsula de tejido $\mathrm{co}^{-}$ nectivo, cuyas prolongaciones en el interior de la glándula dan origen a los lóbulos.

Pesa de 20 a 30 gramos y mide: el istmo 2 X 2 X 0.5 cms. y cada uno de los lóbulos 2 X 2, 5 X 4 cms. Está irrigada por las arterias tiroideas superiores ramas de la corotida externa y las arterias tiroideas inferiores ramas de la subclavia.

\section{FISIOLOGIA}

Está regulada por la tirotropina hipofisiaria (THS) que actuando sobre las células foliculares estimula la liberación y sintesis de tiroxina (T4) y triyodatironina (T3) éstas a la vez, por un mecanismo de retroacción negativa, regulan la síntesis de TSH en la hipofisis, en tanto en el hipotálamo parece que aumentan la síntesis de hormona liberadora de tirotripina (TRH), por un mecanismo de tracción positivo.

La TRH hipotalámica (Piroglutamil Histidil Prolina amida), sintetizada por Shally en 1.971 , estimula las células tirotropas en la hipofisis para que secre ten TSH y en dosis farmacológicas desencadena la liberación y síntesis de prolactina (PRL). 1-2 
La TSH es una glicoproteina que tiene un peso molecular de 35.000 y está constituída. por una subunidad $\propto$, común a las demás glicoproteinas: (FSHLH y HCG) consta de 92 aminoácidos y por una subunidad Beta que es específica y la diferencia de las demás glicoproteinas.

La TSH actúa directamente sobre la glándula tiroides estimulando la liberación y síntesis de tiroxina y triyodotironina.

\section{SINTESIS Y SECRECION DE HORMO- NAS TIROIDEAS'.}

Se describen 4 etapas primordiales para la síntesis y liberación de las hormonas tiroideas.

1. Transporte activo del yodo.

2. Reducción del yodo inorgánico (yoduro) a yodo orgánico (yodo) y yodinación de los residuos de tirosina de la tiroglobulina.

3. Acoplamiento de la mono y diyodotironina para constituir la $\mathrm{T} 3$ y $\mathrm{T} 4$ en forma de gotas de coloide.

4. La proteolisis de la tiroglobulina y la liberación a la circulación sistémica de moléculas de T3 y T4.

\section{TRANSPORTE ACTIVO DEL YODO}

El yodo circulante es captado por la glándula, mediante un mecanismo de atrapamiento activo que se ha denominado "la bomba de yodo". Su mecanismo exacto no es conocido, sólo que es mediado por la TSH.

Se calcula que la glándula necesita unos 75 microgramos diarios de yodo para asegurar una producción hormonal adecuada, pero concentraciones plasmáticas de 200 a 350 microgramos por litro bloquean la captación de yodo por parte de la glándula.

Las necesidades diarias de yodo en la dieta se calculan en unos 15 a $20 \mathrm{cms}$. de los cuales el $30 \%$ es captado por la tiroides y el resto se excreta por el $\mathrm{ri}$ ñón. Ingesta menor de 15 mgs. dará como resultado un balance negativo.

También se concentra yodo pero en menor proporción en los músculos, glándulas salivales, piel, mucosa gástri- ca, glándula mamaria y placenta, pero sólo en la tiroides el yodo está sujeto a una regulación hormonal.

\section{REDUCCION DEL YODO INORGA- NICO Y YODINACION DE LOS RE- SIDUOS DE TIROSINA.}

Una vez en el interior de la célula el yodo inorgánico se reduce a yodo orgánico por acción de las peroxidasas, las cuales a su vez estimulan la yodinación de los residuos de tirosina que se encuentran haciendo parte de la molécula de la tiroglobulina, dando origen a las mono y diyodotironinas.

\section{ACOPLAMIENTO}

Posteriormente las mono y diyotironinas se acoplan en el interior de la molécula de la tiroglobulina para constituir la tiroxina (T4) y la Triyodotironina (T3) dando origen al coloide. Este mecanismo de síntesis hormonal ocurre a nivel de los mitocondrias, luego el coloide sale al citoplasma celular en forma de gotas, el cual es excretado a la luz del folículo tiroideo, por un mecanismo de exocitosis, para almacenarse en su interior.

\section{PROTEOLISIS DE LA TIROGLOBU-} LINA.

Cuando el organismo necesita de hormonas tiroideas, las células foliculares por un mecanismo opuesto, de endocitosis o picnocitosis, retorna el coloide de la luz alveolar.

Una vez el coloide en el interior de la célula se une a los lisosomas, en donde la tiroglobulina sufre una proteolisis activa, por acción de enzimas hidrolíticas, liberando así las hormonas tiroideas, las cuales son secretadas en forma libre a la circulación sistémica y quedando en el interior de la célula, mono yodo y diyodotironinas, las cuales a su vez son deshalogenadas en el tiroides, quedando el yodo libre y disponible para nueva síntesis hormonal. Se calcula la secreción diaria de tiroxina en 56 mgs. y de triyodotironina en 32 mgs. (3).

La tiroglobulina es una glicoproteina básica para la síntesis de hormonas tiroideas, su peso molecular es de 660 . 
000. Contiene en su estructura un $15 \%$ de carbohidratos, alrededor de 115 a 120 residuos de tirosina, de las cuales sólo un $30 \%$ son yodadas y con una relación T4: T3 de 3:1.

\section{TRANSPORTE DE LAS HORMONAS TI- 3OIDEAS:}

Las hormonas tiroideas tienen una estrucura molecular muy simple, son monoaninas yodadas, su transporte y mecanisno de acción es muy peculiar en relación l las demás hormonas protéicas, a diferen:ia de ellas, las hormonas tiroideas circuan unidas a una globulina transportadora $\checkmark$ en su mecanismo de acción tienen una cierta semejanza con las hormonas este-oides, al ser capaces de atravezar librenente la membrana celular y actuar a nivel nuclear. Fig. No. 1.

Las hormonas tiroideas una vez en la cirzulación sistemática se unen a las proteínas transportadoras con el objeto de evitar la desintegración rápida de la hormona, quedando sólo una pequeña cantidad libre que es la que verdaderamente tiene acción hormonal.

La tiroxina tiene una gran afinidad a la I'BG (globulina transportadora de hormonas tiroideas) a la que se une un $75 \%$ de la hormona, el $20 \%$ restante se une a la TBA (albúmina transportadora de hormonas tiroideas) y sólo un $5 \%$ a la TBPA (prealbúmina transportadora de hormonas tiroideas).

La triyodotironina es transportada también por la TBG, pero con una menor afinidad por lo cual es desplazada fácilmente por la $\mathrm{T} 4$, lo que da como resultado que el $95 \%$ de la hormona tiroidea circulante es T4 y sólo un $5 \%$ es T3. La concentración plasmática de T4 es 4.5 a 11 microgramos $100 \%$, de los cuales están 0 . $025 \mathrm{ng} / \mathrm{ml}$ en forma libre, representando el $0.04 \%$ del total de la hormona, en tanto a concentración de T3 es de 75-220 ng\% de las cuales están en forma libre el $0.4 \%$ del total (3-23-25).

\section{METABOLISMO DE LAS HORMONAS TIROIDEAS.}

Las hormonas tiroideas se distribuyen en la circulación sistémica a todos los tejidos en donde ejercen acciones importantes a nivel de la síntesis protéica, metabolismo

\section{y respiración celular.}

Se considera que de los 56 mgs de T4 producidos por la glándula, un $30 \%$ se transforma a T3, un $20 \%$ es excretado en la materias fecales previa conjugación hepática y el resto es metabolizado a nivel celular en las diferentes reacciones en que participa, estando concentrado en el higado alrededor de un $30 \%$ de la T4 extratiroidea. La vida media de la tiroxina es alrededor de 6 a 8 días.

En relación a la T3, sólo el $20 \%(7 \mathrm{mgs})$ es producido en la glándula y el $80 \%$ (25 mgs) se origitha de la deyodinación de la T4 para un total de 32 mgs, de los cuales sólo un $5 \%$ se elimina por las materias fecales y el $95 \%$ restante se distribuye en todo el organismo, en el interior de las células.

La vida media de la T3 es de 2 a 3 días sin embargo es 3 a 4 veces más potente biológicamente que la $\mathrm{T} 4$, de allí que el $66 \%$ de la actividad biológica sea por T3 y sólo un $33 \%$ por $\mathrm{T} 4$; además se encuentra una alta concentración de T3 en los tejidos en relación al plasma todo esto hace pensar que T3 sea la verdadera hormona y T4 su precursora.

\section{MECANISMO DE ACCION HORMONAL}

Las hormonas tiroideas no sólo intervienen en el metabolismo y respiración celular sino que actúan en la síntesis protéica, la cual parece ser su función específica.

La T3 y la T4 a semejanza de las hormonas esteroides pasan fácilmente la membrana celular luego de separarse de las proteinas transportadoras, ya en el interior de la célula circulan libremente por el citoplasma sin unirsen a ningún receptor del citosol, para pasar luego al núcleo en donde se encuentran receptores específicos para T3, de allí que el $90 \%$ de hormonas tiroideas en el núcleo sea T3 (4). Estas diferencias hacen que el mecanismo de acción de las hormonas tiroideas sea específico y las diferencie del mecanismo de acción de las hormonas protéicas y de los esteroides.

\section{PAPEL DE LAS HORMONAS TIROI- DEAS SOBRE LA FUNCION HORMO- NAL.}


a. A nivel de las hormonas protéicas.

Estas hormonas se unen a un receptor de naturaleza protéica situado en la membrana celular y que es específico para cada hormona, conformando el complejo receptor-hormona, el cual activa la adenilciclasa en el interior de la membrana, al parecer mediada por los prostaglandinas.

La adenilciclasa activada actúa en el citoplasma sobre la molécula de ATP, fraccionándola en 3', 5' AMP cíclico. El cual a su vez se une a la fracción receptora $(R)$ de la proteina-quinasa, liberando la fracción catalítica (C), la cual se encarga de activar las enzimas que se encuentran en el citoplasma por medio de la fosforilación, utilizando el ATP. Estas enzimas fosforiladas intervienen en la sfntesis de nuevas hormonas protéicas o esteroides de acuerdo a la célula donde actúen. Fig. No. 2.

Las hormonas tiroideas tienen un papel permisivo en cada una de estas etapas y su alteración trae como consecuencia graves trastornos hormonales.

En el hipertiroidismo se encuentra un aumento de la actividad de la adenilciclasa posiblemente por aumento en la activación de la enzima, mecanismo que se ha observado en estudios in vitro en fibras de miocardio (5) y en los espermatozoides de micos (6), sin em. bargo este mecanismo no ha sido aún descrito en todos los tejidos, además la hormona tiroidea compite con la fosfodiesterasa impidiendo la destrucción del 3', 5'. AMPc, en esta etapa la $\mathrm{T} 4$ es un $30 \%$ más potente que la T3 en la acción competitiva (8-9). Este mecanismo dual trae como consecuencia en el hipertiroidismo un aumento en la concentración de 3', 5' AMPc, que siendo determinado en niveles basales no se aprecia diferencia significativa en relación a las eutiroideas o hipotiroideas, pero al someter a estas pacientes a un estímulo hormonal Pe: Aplicación parenteral de Norepinefrina, glucagon o paratohormona se aprecia un aumento significativo del 3', 5' AMPc plasmático en los hipertiroideas en relación a las eutiroideas e hipotiroideas (7). Tanto por el aumento en la concentración del 3', 5' AMPc como por el estímulo en el funcionamiento de la mitocondria ejercido por la hormona tiroidea, la que a su vez ejerce un ef ecto positivo sobre el ribosoma, trae como resultado final un aumento en la síntesis protéica (8). Cuadro No. 1 y Figs. Nos. 3 y 4.

\section{b. A nivel de Hormonas esteroides}

La hormona tiroidea y específicamente la T3 tiene una mayor apetencia para unirse a receptores nucleares lo cual dá como resultado que el $90 \%$ de la hormona a nivel nuclear sea T3 (10). Se ha demostrado que cuando los receptores nucleares están ocupados por T3, hay una adecuada respuesta biológica a la acción hormonal (11).

Según TaTa, (12), las hormonas tiroideas actúan facilitando la transcripción del DNA necesarias para la síntesis de la nueva proteina, esto hace pensar que la hormona tiroidea en cantidades fisiológicas facilita la transcripción del mRNA, t RNA y $r$ RNA necesarios para la síntesis hormonal, que se alteraría tanto en el hipertiroidismo por bloqueo debido al exceso de hormona tiroidea intracelular como en el hipotiroidismo por falta de la acción permisiva de la hormona. Fig. No. 5.

\section{c. A nivel de la síntesis de catecolaminas}

Para comprender las alteraciones endocrinas que se presentan en los trastornos tiroideos es necesario conocer los cambios que se presentan a nivel de la sintesis de catecolaminas. Se sabe que las catecolaminas se originan a partir de un aminoacido esencial: la tirosina, que se transforma a DOPA (dihidroxifenilalanina) por medio de una tirosina beta hidroxilasa y a dopamina por la dopamina decarboxilasa y esta a Noradrenalina por la dopamina beta hidroxilasa (DBH). Todo este mecanismo de sintesis de catecolaminas se altera durante los trastornos tiroideos así: En el hipertiroidismo se ha encontrado un aumento de la dopamina sérica debido a la disminución de la dopamina beta hidroxilasa (13) y como consecuencia se encuentra disminución de los niveles séricos de Norepinefrina y aumento de la síntesis de PIF y por ende disminución de prolactina. Además se observa como consecuencia una pobre respuesta al estímulo con TRH I.V. en relación a la secreción de TSH y de PRL. 
En las pacientes hipotiroideas ocurre lo inverso (14), se aprecia disminución de los niveles de dopamina y por lo tanto se disminuye la síntesis de PIF lo cual desencadena los estados de hiperprolactinemia.

Yamají conceptúa que la tiroxina modula a nivel hipotalámico tanto la liberación de TSH como de PRL (20) y aún parece que de gonadotropinas.

La hormona tiroidea no solo actúa sobre el mecanismo de síntesis de catecolaminas sino que también lo hace en la etapa de recaptación a nivel del axón (15). Normalmente las catecolaminas liberadas al espacio intersináptico se adhieren a los receptores de membrana dẹ la célula postsináptica y una pequeña cantidad que no se ha utilizado entra nuevamente a la célula presináptica por un mecanismo de recaptación. Este mecanismo es bloqueado en las pacientes hipertiroideas lo cual explicaría el síndrome de hiperestimulación simpática a pesar de encontrarse niveles plas máticos bajos de Norepinefrina en estas pacientes, por el contrario en pacientes hipotiroideos se encuentran niveles elevados de catecolaminas (14). Cuadro 2 .

\section{HIPERTIROIDISMO}

Las pacientes hipertiroideas presentan diversos trastornos del ciclo relacionados con la gravedad de la enfermedad, inicialmente consultan por poli e hipermenorreas, abortos del primer trimestre y finalmente oligo, amenorreas y esterilidad.

Gracias a las determinaciones hormonales por radioinmunoanálisis ha sido posible conocer mejor los trastornos endocrinos en hipertiroideas, es asi como Akande estudiando 15 mujeres tirotóxicas describió trastornos no sólo en la secreción de hormonas protéicas sino de las esteroides (16). Los cambios más importantes en relación a mujeres eutiroideas se encuentran a nivel de la secreción de gonadotropinas. La LH se eleva en un $25 \%$ tanto en la fase folicular como en la luteínica, en tanto el pico de la $\mathrm{LH}$ desciende en un $33 \%$, hallazgo que explicaría la alta frecuencia de ciclos con cuerpo láteo insuficiente y aún ciclos anovulatorios; en tanto es menor las modificaciones a nivel de la secreción de FSH, se elevan los niveles plasmáticos en un $60 \%$ en la fase folicular y en un $50 \%$ en la luteínica, no ocurriendo cambios im- portantes sobre el pico ovulatorio. En cuanto a los estrógenos totales en plasma, también sufren modificaciones, se elevan en un $230 \%$ en la fase folicular, en un $200 \%$ en la luteínica y durante el pico preovulatorio hasta en un $300 \%$. Sin embargo a pesar de la elevación de estrógenos totales plasmáticos, las hipertiroideas tienen una concentración baja de estrógenos libres, debido al aumento de la síntesis hepática TeBG(globulina transportadora de testosterona y estrógenos) pór la acción estimulante de la tiroxina.

La disminución de los estrógenos libres en concentraciones por debajo del nivel crítico como la alteración en la síntesis de catecolaminas y la existencia de una mayor excitabilidad del sistema nervioso central, trae como resultado alteración en los mecanismos de retroacción y por ende trastornos a nivel de la secreción de gonadotropina, por lo cual sería necesario la regulación del nivel de la secreción de hor monas tiroideas y mayor concentración de estrógenos libres para modificar la secreción de gonadotropinas (17). Cuadros $1,2,3,4,5$ y 6 .

También los tejidos ef ectores a los estrógenos (endometrio, vagina y cuello), son refractarios a la acción de los estrógenos, en parte porque los estrógenos libres se encuentran disminuídos y principalmente debido a que el sistema de reduplicación del DNA se encuentra alterado por la acción bloqueadora de los niveles elevados de la hormona tiroidea, dando como resultado un trastorno en la respuesta hormonal, lo que explicaría la alta frecuencia de oligomenorreas y amenorreas, por endometrios proliferativos y aún atróficos.

En el hombre el hipertiroidismo desencadena la aparición de ginecomastia bilateral, pues aunque los estrógenos libres están disminuídos en relación a las mujeres, en el hombre son suficientemente altas para ejercer una acción trófica sobre la glándula mamaria, además produce esterilidad como consecuencia de la disminución en el recuento y movilidad de los espermatozoides (18).

\section{HIPOTIROIDISMO}

Las pacientes hipotiroideas presentan alteraciones del ciclo menstrual consistentes en oligomenorreas, amenorreas y menorragias dando como resultado final la esterilidad. 
Concentración plasmática de AMPc basal y a la estimulación con Epinefrina (0.05 $\mu \mathrm{g} / \mathrm{kg} / \mathrm{min}$ )

$\begin{array}{lcr} & \text { Basal }(n M) & 60 \text { minutos } \\ \text { Eutiroidea } & 17.1 \pm 0.6 & 42.3 \pm 2.6 \\ \text { Hipotiroidea } & 20.5 \pm 1.7 & 27.3 \pm 3.2 \\ \text { Hipertiroidea } & 23.5 \pm 1.3 & 58.7 \pm 5.7\end{array}$

Cuttler R.y Cols. Metabolism. 26: $1155,1977$. 


\section{Concentración plasmática de Norepinefrina en los estados tiroideos-(ng/ml).}

Eutiroidea

Hipertiroidea

Hipotiroidea
$18.3 \pm 4.2$

$17.5 \pm 3.9$

$30.3 \pm 2.94$

\section{Coulombe P.y Col JCEM $44.1185,1977$.}

Algunas pacientes consultan por mastodinia y galactorrea, ocasionalmente es causa de pubertad precoz como resultado de los múltiples trastornos endocrinos (26-27).

En la evaluación ginecológica se aprecia galactorrea bilateral, atrofia vaginal, uterina y endometrial. El índice cariopicnótico muestra células basales y parabasales en la citolog ́a vaginal.

Luego de las alteraciones hormonales descritas por AKANDE en pacientes hipotiroideas se ha podido demostrar mejor los trastornos a nivel del sistema gonadal con relación a mujeres eutiroideas, tales como disminución de los niveles plasmáticos de FSH en un $30 \%$ de LH en un $55 \%$, ausencia del pico ovulatorio de $\mathrm{FSH}$ y LH y disminución hasta de un $70 \%$ de los niveles plasmáticos de estrógenos totales cuadros 7 y 8.

A nivel de las catecolaminas se encuentra disminución de la síntesis de dopamina que trae como consecuencia la hiperprolactinemia que se encuentra en estas pacientes debido a la disminución de la síntesis del factor inhibidor de prolactina (PIF); además disminución de los niveles plasmáticos de gonadatropinas como resultado de:
1. Alteración a nivel de la síntesis de catecolaminas que regulan el adecuado funcionamiento del centro tónico y cíclico, el cual es mediado por los estrógenos.

2. Alteración de los mecanismos de las hormonas protéicas originando trastornos de la síntesis hormonal al disminuir los niveles de 3' 5' AMPc bien por disminuir la síntesis y aumento de la degradación por acción de la fosfodiesterasa.

En cuanto a la disminución de los niveles plasmáticos de estrógenos totales se debe a la falta del papel permisivo de las hormonas tiroideas a nivel nuclear.

Estos trastornos endocrinos también trae como consecuencia una lenta respuesta hipofisiaria a estímulos exógenos tales como la aplicación parenteral de GnRH (240y TRH) (25).

Todos estos trastornos endocrinos son el resultado de la ausencia de niveles adecuados de la hormona tiroidea, necesarios en cada una de las etapas de la acción hormonal. 
Hormonas tiroideas

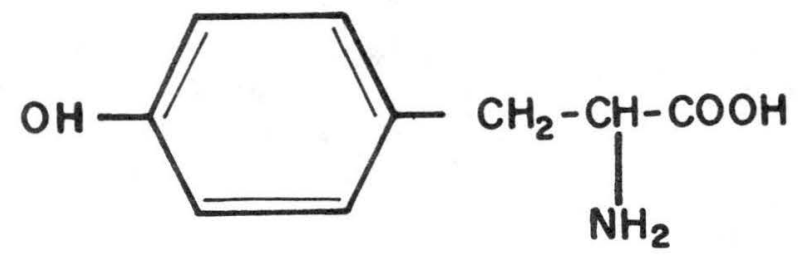

Tirosina
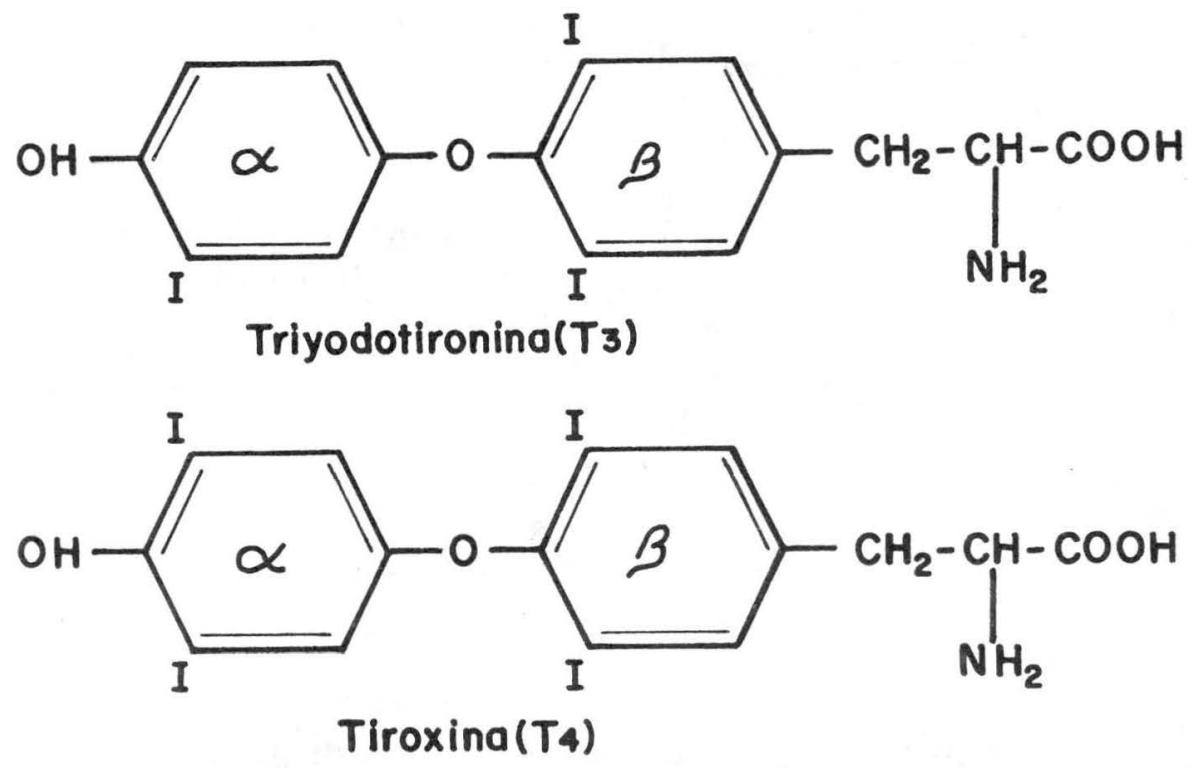

Figura No. 1 


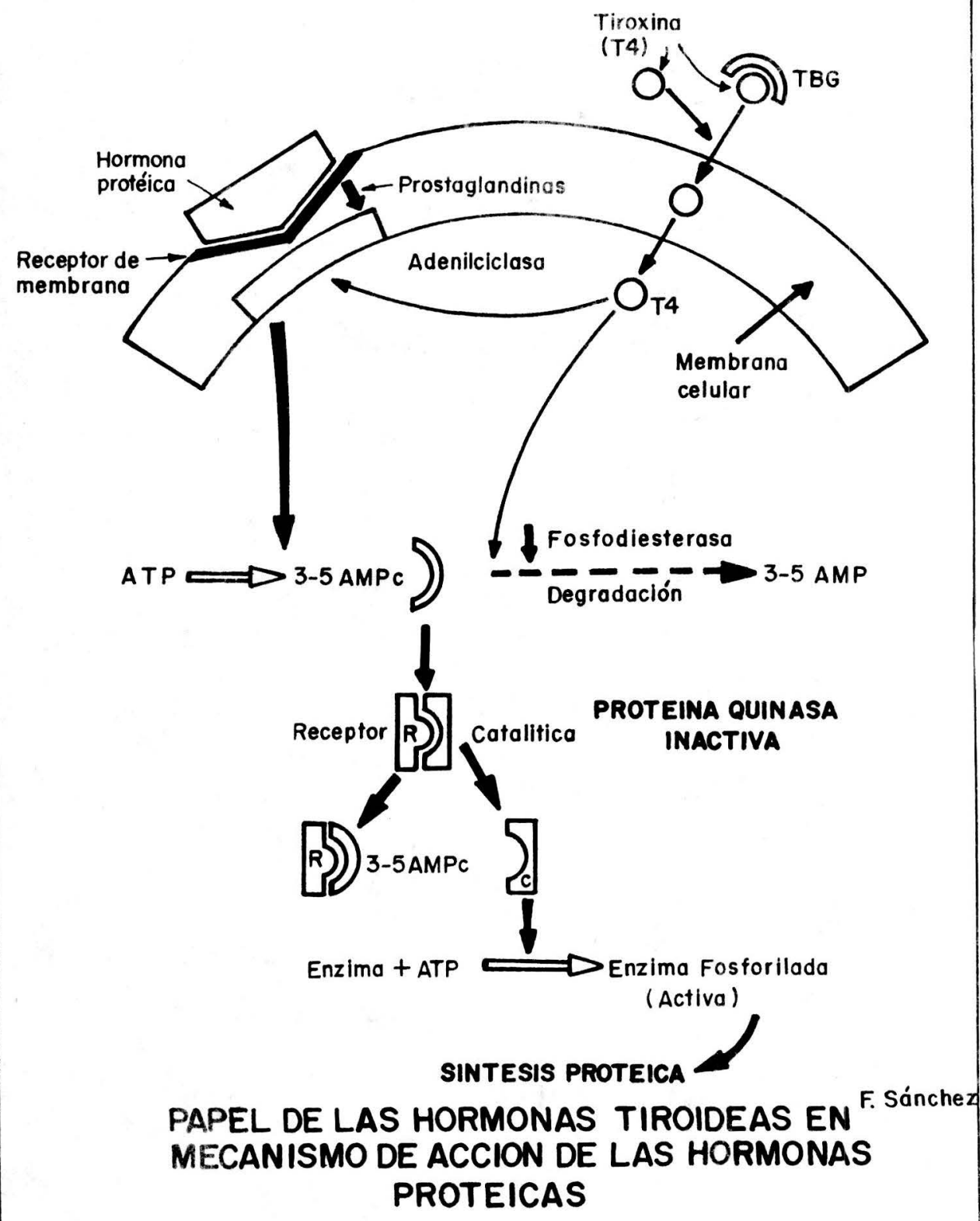

Fig. No. 2 


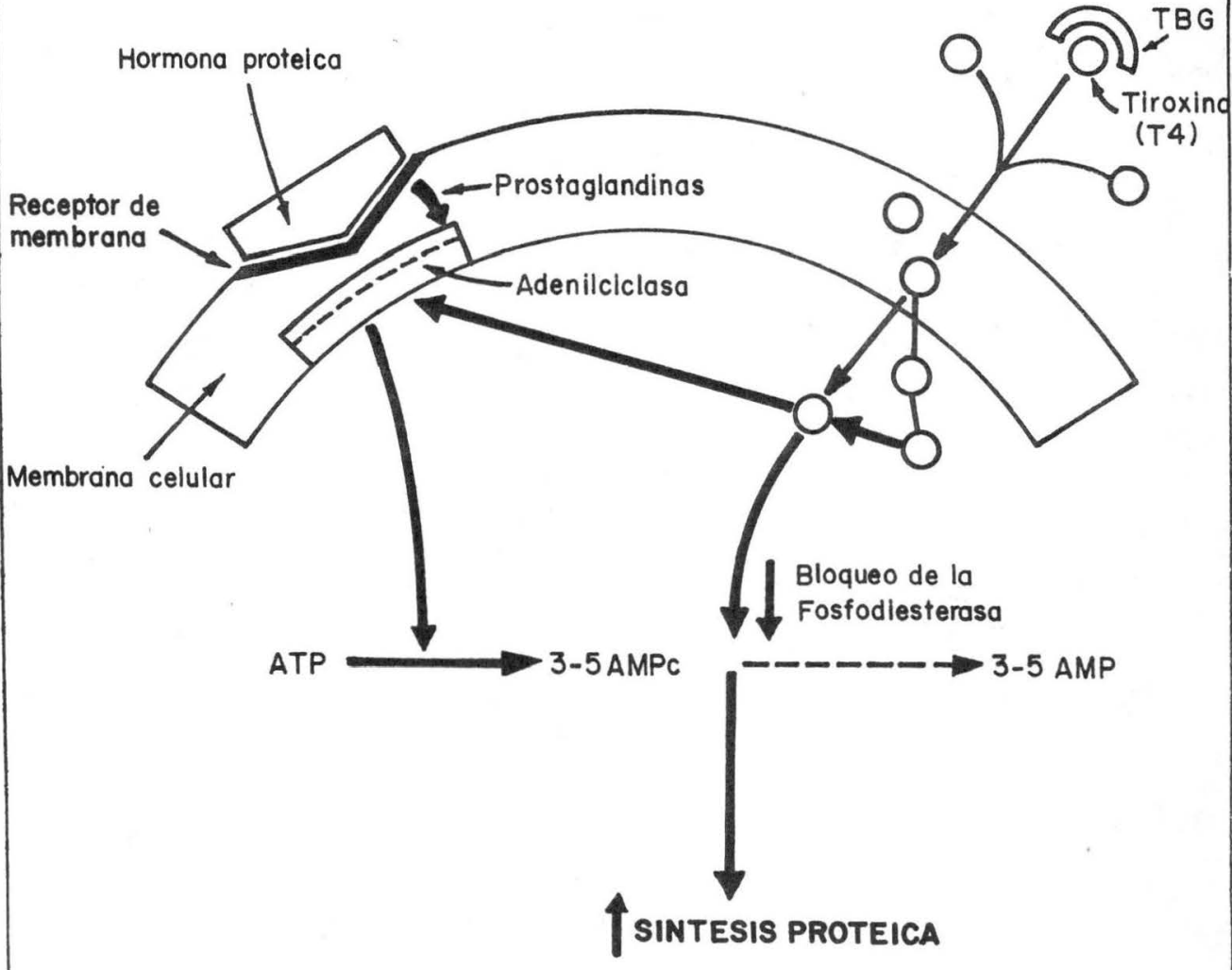

HIPERTIROIDISMO

F. Sánchez

PAPEL DE LAS HORMONAS TIROIDEAS EN MECANISMOS DE ACCION DE LAS HORMONAS PROTEICAS

Figura 3 


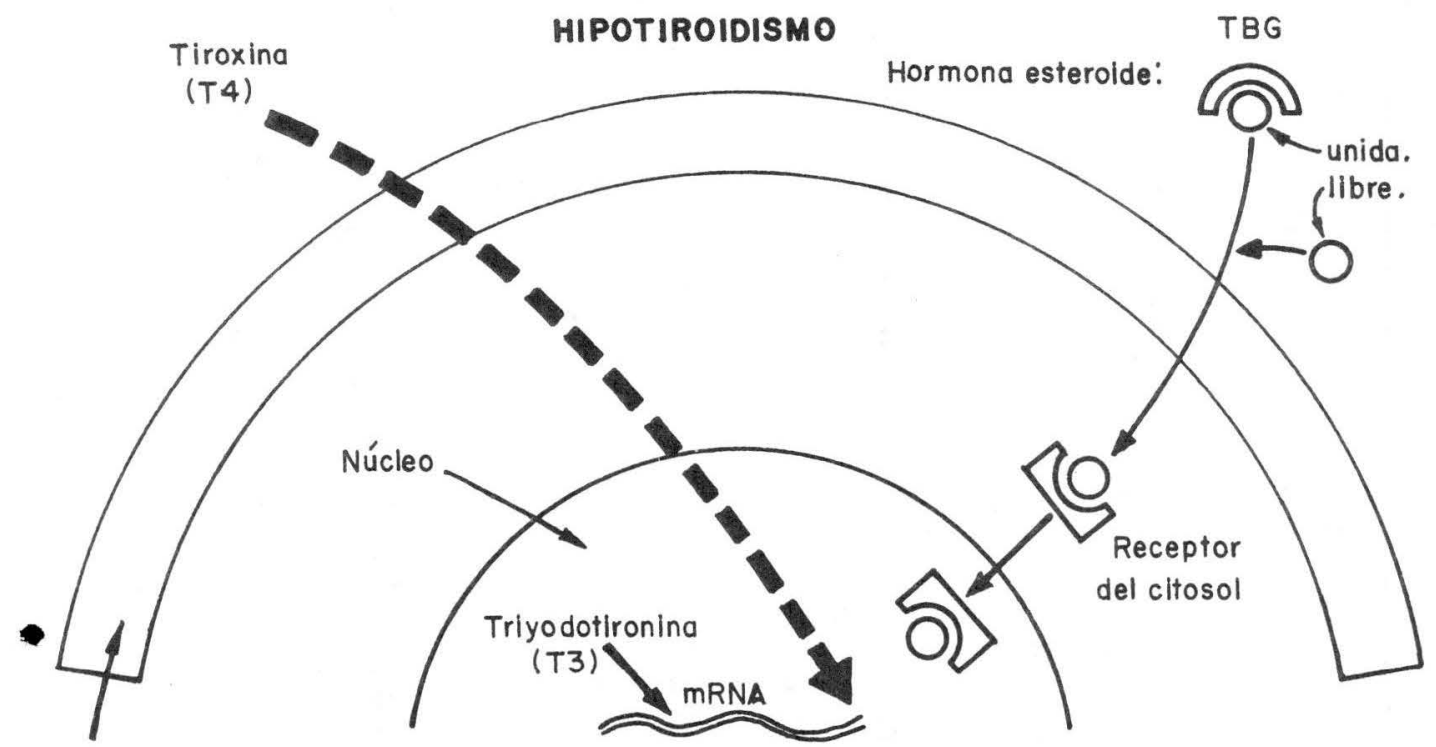

riroxina (T4)

Membrana celular
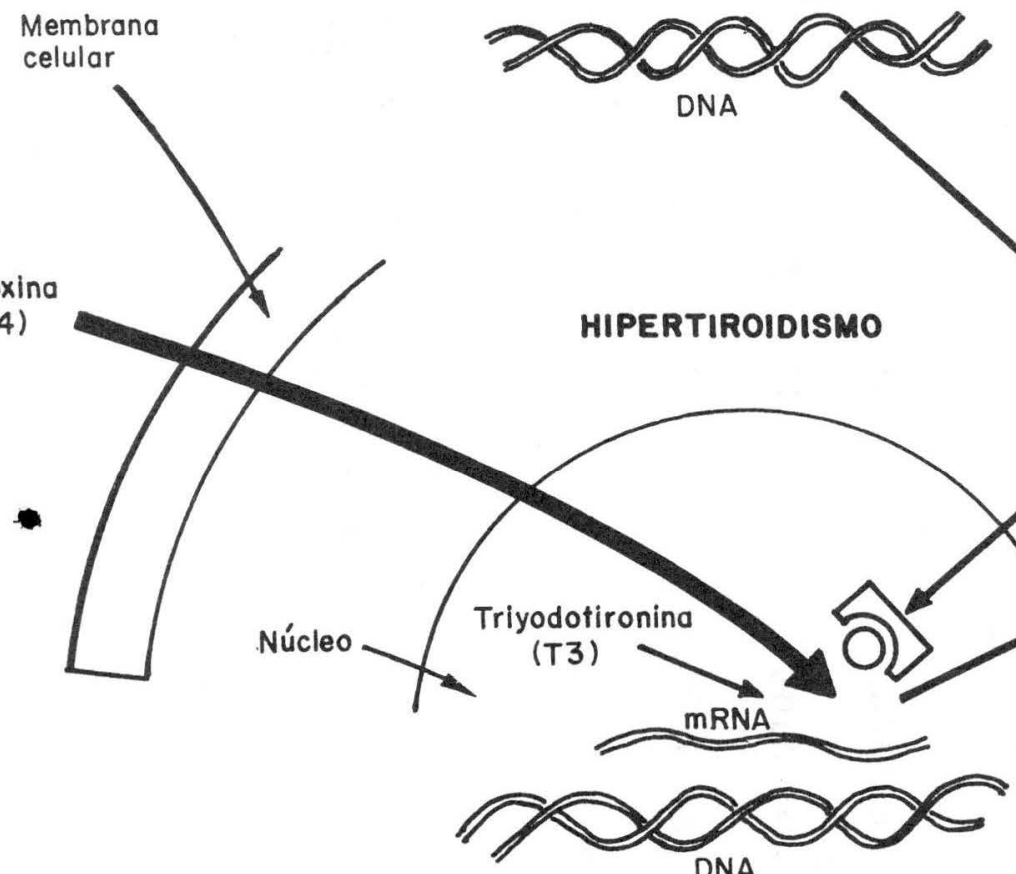

F. Sánchez

PAPEL DE LAS HORMONAS TIROIDEASEN EL MECANISMO DE ACCION DE LOS ESTEROIDES

Figura 5 
Niveles de LH en 10 mujeres tirotoxicas y 12 eutiroideas durante el ciclo menstrual ( $\mathrm{m} U 1 / \mathrm{ml}$.).

$\begin{array}{llcc}\text { Estado: } & \text { Fase folicular: } & \text { Día } 0: & \text { Fase lutea: } \\ \text { Eutiroideas } & 10.9 \pm 0.6 & 120.2 \pm 22.7 & 9.8 \pm 0.6 \\ \text { Hipertiroideas } & 26.5 \pm 2 & 85.2 \pm 13.7 & 25.4 \pm 3.4 \\ \text { Con tratamiento } & 11.0 \pm 1.4 & 110.2 \pm 20.6 & 10.0 \pm 0.8 \\ & & \text { Akande E0. Brit J. Obst. Gyn. } \\ & 82: 541,1975 . \\ & & \end{array}$




\section{Niveles de FSH en 10 mujeres tirotoxicas y 12 eutiroideas}

durante el ciclo menstrual ( $\mathrm{m} \mathrm{UI} / \mathrm{ml}$ ).

$\begin{array}{cccc}\text { Estado: } & \text { Fase folicular: } & \text { Día } 0: & \text { Fase lutea: } \\ \text { Eutiroidea } & 11.1 \pm 0.9 & 34.3 \pm 3.8 & 10.6 \pm 0.9 \\ \text { Hipertiroidea } & 18.3 \pm 1.4 & 37.9 \pm 5.0 & 16.9 \pm 1.4\end{array}$

Akande EO. Brit J. Obst. Gyn.

82: $541,1975$. 


\section{Niveles de estrógenos totales en plasma en 10 mujeres - tirotoxicas y 12 eutiroideas $(\mathrm{ng} / \mathrm{ml}$ ).}

$\begin{array}{llccc} & \text { Fase folicular: } & \text { Día } 1: & \text { Día } 0: & \text { Fase lutea : } \\ \text { Eutiroideas } & 14.8 \pm 1.3 & 42.6 \pm 6.2 & 19.9 \pm 4.3 & 20.3 \pm 2.2 \\ \text { Hipertiroideas } & 33.0 \pm 3.8 & 91.3 \pm 10.4 & 70.0 \pm 13.3 & 39.4 \pm 4.5\end{array}$

Akande EO. Brit J. Obst. Gyn.

$82: 541,1975$. 
Niveles plasmáticos de TeBG en 15 mujeres tirotoxicas y 12 eutiroideas $\left(10^{8}-M\right)$
Eutiroideas
$7.9 \pm 1.9$
Tirotoxicas
$17.8 \pm 3.5$
Con tratamiento
$8.2 \pm 1.3$

Akande EO.Brit J. Obst. Gyn.

$82: 541,1975$. 
Niveles de FSH y LH en 5 mujeres hipotiroideas y 12 eutiroideas $(\mathrm{m} \mathrm{Ul./} \mathrm{ml}$.)

Eutiroideas $\quad\left\{\begin{array}{lcc}\text { Fase folicular. } & \text { LH } & \text { FSH } \\ \text { Fase lutea. } & 10.9 \pm 0.6 & 11.1 \pm 0.9 \\ \text { Hipotiroideas } & 9.8 \pm 0.6 & 10.6 \pm 0.9 \\ & 4.7 \pm 0.4 & 7.7 \pm 0.2\end{array}\right.$

Akande EO. Brit J. Obst. Gyn. $82: 541,1975$. 


\section{Niveles de estrógenos en plasma en 5 mujeres- hipotiroideas y 12 eutiroideas $(\mathrm{ng} / 100 \mathrm{ml})$}

Eutiroideas $\left\{\begin{array}{l}\text { a) Fase folicular } \\ \text { b) Fase lutea }\end{array}\right.$

Hipotiroideas
$14.8 \pm 1.3$

$20.3 \pm 2.2$

4. $3 \pm 0.3$

\section{Akande EO. Brit J. Obst. Gyn. $82: 541,1975$.}

CUADRO No. 8

\section{R E S U M E N}

Se hace una actualización sobre el tema de tiroides y su influencia sobre la función gonadal.

Desde los estudios de embriología, histología y anatomía, hasta el de fisiología endocrina del tiroides, todos son llevados a cabo en forma compendiada y ordenada, insistiendo en la síntesis química y la secreción de las hormonas tiroideas, el metabolismo del yodo inorgánico y la proteolisis de la tiroglobulina. El transporte y el metabolismo de las hormonas tiroideas al igual que el del yodo y sus mecanismos de acción hormonal, así como el papel de la hormona tiroidea sobre toda la función hormonal, ocupa gran parte del estudio. Por ultimo, una sinopsis clínica sobre hiper e hipotiroidismo complementa el trabajo llevado a cabo.

\section{SUMARY}

,The subject on thyroid and its influen- ce on gonadal function is updated.

All studies, from embriology, histology and anatomy up to thyroid endocrine physiology, are carried out in a summarized and ordered way, emphasizing chemical synthesis and thiroid hormones secretion, inorganic iodine metabolism and thyroglobuline proteolysis. Thyroid hormones transportation and metabolism as well as iodine and its hormonal action mecanisms and the roll of thyroid hormone over all hormonal action are covered in great part of the study. Finally, a clinical synopsis on hyper and hypothyroidism completes the work carried out.

\section{B I B LIO G R A F I A}

1. Engbar SH, Woeber KA. The Thyroid gland. Textbook of endocrinology Fifth edit. Philadephia. WB Saunders Co. 1.974. P. 95.

2. Folkers Gwetal: Biorhem Biophys Res Commun 37: $123,1.969$.

3. Greenspan FS. Thyrodid-gonadal interrelationships. Gynecol Endocrin. Second edit. 
Edited: Jay Gold. Harper and Row, Publishers Hagerstoen 1.975 P. 99.

4. Tata JR. How Specific are neclear receptors for thyroid gormones. Nature 275: 19,1.975.

5. Levey GS. and Epstein SE. Myocardial Adenil Tyclase: Activation by Thyroid Hormones and evidence for two adenyl Cyclase Systems. J. clin Invest 48: $1.663-1.969$.

6. Casillas ER and Hoskins. Biochem Biophys Res Common 40: 255, 1.970.

7.i Cuttler RB. Effects of thyroid hormone on plasma adenosine 3,5 Monophopnate production in man, Metabolism 26: 1155, 1.977.

8. Salomon SS: Phosphodiesterase activity of rat and human adipose tissùe J. Lab Clin. Medic 79: $598,1.972$.

9. Marcus R: Cyclic necleotide phosphodiesterase from bone. Characterization of the enzime and studies of inhibition by Thyroid hormone. Endocrino 96: 400, 1.975.

10. Mandel LR and Kuehl F: Biochem Biophys Res Emmon 28: 13, 1.971.

11. Openheimer JH. and Surks MT. The periferical action of the thyroid hormones. Medic Clin NA 59: 1055, 1.975.

12. Tata JR and Widnell CC: Ribonucleic acid Synthesis during the early action of thyroid hormone. Biochem J. 98: 604. 1.966.

13. Spauldin SE and Noth RH Thyroid - Cathecolamine Interactions Medic Clinic N Amer. 59: $1123,1.975$.

14. Coulombe P, Dussault JH, Walker P. Catecholamine metabolism in thyroid desease II. Norepinephrine secretion rate in Hyperthiroidism and hypothyroidism. JCEM 44:1185, 1.977 .

15. Wurman RJ, Kopin and Axelrod J: Thyroid functiond and disposition of catecholamines. Endocrinol 73: 63, 1.973.

16. Akande EO and Hokanday TDR-Plasma concentration of gonadotrophins, Oestrogen and progesterone in Thyrotoxic Women. Brit J. Obstet Ginecol. 82: 541, 1.975.

17. Akande EO and Anderson DC. Role of sexhormone binding globulin in hormonal changes and amenorrhoea in thyroid women. Brit J. Obstet gynec 82: $557,1.975$.

18. Clyde HR, Walsh PC, English RW: Elevated plasma testosterone and Gonadotrophin levels in infertle maes with hyperthyroidismFertil. Steril 27: 662. 1.976.

19. Akande EO Plasma concentration of gonadotrophins, Oestrogen and progesterone in hy pothy roid women. Brit J. Obstet ginecol. 82: 552.

20. Yamaji T: Modulation of prolactin release by altered level of thyroid hormones, Metabolis 23:745.

21. Bernal J, Refetoff S. The action of thyroid hormone. Clin Endoc. 6: 227, 1.976.

22. Yamada T. Control of thyroid Hormone Secretion. Pharm Ther 1.3, 1.976.

23. Martin CR. Thyroid hormones in Texbook endocrine Physiology first edit. Williams Co, Baltimore 1.975 Pg. 189.

24. Distiller L.A, Sagel J. Morley J. Assesment of Pituitary Gonadotropin Reserve using Luteinizaing Hormone Releasing Hormone (LR $\mathrm{H})$ in States of altered Thy roid function. J. Clin Endocrinol Metabl 40: 512, 1.975 .

25. Orrego A. Enfermedades de las Glandulas

25. Orrego A. En fermedades de las Glándulas Endocrinas. Glándula Tiroides. Fundamentos de Medicina-primera edic. universidad de Antioquia 1.970 Pg. 433.

26. Costin G, Kershnar AK, Kogut MD, Turkington RW. Prolactin Activity in juvenile Hypothyroidism and precocious puberty. Pediatrice 50: 881, 1.972 .

27. Keye WR, Yuen BH, Knope RF, Jaffe RB. Amenorrhea, Hy perprolactinemia, and Pituitary Enlargement Secondary to Primary Hy pothyroidism. Obst-Gy nec. 48: 697, 1.976 . 